\title{
THE CHALLENGE OF IMPLEMENTING ONLINE INTERPROFESSIONAL EDUCATION FOR UNDERGRADUATE STUDENTS: A LITERATURE REVIEW
}

\author{
Rilani Riskiyana ${ }^{1^{*}}$ \\ ${ }^{1}$ Department of Medical Education and Bioethics, Faculty of Medicine, Public Health and Nursing, Universitas Gadjah Mada, \\ Yogyakarta - INDONESIA
}

Submitted: 18 Apr 2020; Final Revision from Author: 19 Oct 2020; Accepted: 29 Dec 2020

\begin{abstract}
Background: Interprofessional education (IPE) is undergoing vast development recently. Online learning has been proven to help overcoming the barriers that were commonly found in traditional IPE. However, the management of online learning in IPE is not well understood. The study identified challenges in online learning in IPE as well as recommendations for better program implementation.

Methods: A literature review was performed using several keywords including "online learning", "blended learning", "interprofessional education", "challenges", and "obstacles". The databases included EBSCOHost, ProQuest, Google Scholar, and Sciencedirect. A narrative analysis was performed to meet the review objective.

Results: The identified challenges in establishing online learning for IPE were categorized according to each phase, i.e. planning and implementation. Seven categories of challenge were highlighted. The recommendations to overcome each challenge were also discussed for better implementation in the future.

Conclusion: Understanding the possible challenge in each phase of developing online learning for IPE could minimize the potential disruption in achieving the learning objective. Gaining support as well as faculty trainings are crucial to ensure the program sustainability.
\end{abstract}

Keywords: interprofessional education, online learning, blended learning, challenge

\section{PRACTICE POINTS}

- The paper address challenges in developing and managing online learning in IPE.

- The paper discuss recommendations on how to deal with the possible constraint in implementing online learning for IPE.

*corresponding author, contact: rilani.riskiyana@ugm.ac.id 


\section{INTRODUCTION}

The need for developing online learning for IPE has been growing enormously over the past decade. Online learning is argued to improve learner participation for post millennial generation. ${ }^{1}$ Previous study $^{2}$ shows that institutions across countries have embedded online learning in their IPE, be it blended or full online program. Social media, websites, and Learning Management System (LMS) are the most common platform used as a learning resource for online learning. ${ }^{3}$ The core competences of IPC as mentioned by the Interprofessional Education Collaborative ${ }^{4}$ consists of value and ethics, interprofessional communication, roles and responsibilities, as well as teams and teamwork. Online learning in IPE is apparently advantageous to improve professional understanding. ${ }^{5}$ It helps students learn about their own professional identity and, at the same time, understand the role of other health care professionals. ${ }^{6}$ By understanding the role sharing and how the health care team works, students could develop their orientation toward patient safety. ${ }^{7,8}$ One study ${ }^{9}$ shows that a high fidelity online IPE improved all aspect of interprofessional competence i.e. communication, collaboration, roles and responsibilities, patient-centeredness, conflict management and team functioning. Nevertheless, even without sophisticated learning resource, online learning activity is still useful to help improving student interprofessional collaboration (IPC) competence if designed properly.

Teachers by far reacted positively towards facilitating online IPE activities. ${ }^{3}$ The flexibility value of online IPE provide convenience and improve teaching perceptions. E-learning platform also ease the logistical issues in the delivery of IPE. ${ }^{7}$ Moreover, online learning reinforces the opportunity of multiinstitutional collaboration in implementing IPE. ${ }^{10}$ Developing online or blended learning for IPE requires effort and resources. As the previous study says, the main value of online IPE lies on the flexibility for both the teachers and learners. Therefore, the course developer need to work hard in the preparation to provide convenience during the IPE process. Carefully scrutinizing the academic calendars of each study programs is mandatory during course development. ${ }^{6}$

Based on the premises, online learning is seen to be potential for further development of IPE. It is argued to best suits the learner characteristic nowadays. The literature for online or blended format of IPE, however, is scarce. Understanding how online learning works best for IPE is important to help developing an effective program, including the recommendations for better implementation. A further study is needed to identify the challenges upon embedding online learning into IPE.

\section{METHODS}

This is a literature review of the challenges or obstacles commonly found during the establishment of online or blender learning for IPE. The ultimate projection of the study is providing insight for the IPE designers of challenges to expect as well as recommendations to overcome the possible constraint. The review process was conducted from June to July 2020 toward EBSCOHost, ProQuest, and Sciencedirect to search for the relevant literature. The inclusion criterion in selecting articles include:

- Open-access original research

- Published during period of 2011-2020

- Population: medical and health professions undergraduate students or teachers

- Intervention: interprofessional education program embedding online or blended learning

- Context: student or teacher perception in regards to challenges or obstacles found in online delivery of IPE

- Outcome: student or teachers' evaluation in regards to the attainment of interprofessional competencies.

The exclusion criterion were:

- Continuing or postgraduate-level IPE

- The article solely focus on the achievement of learning objectives without discussing the evaluation of the program.

The selection process was performed as described in Figure 1. The keywords were "interprofessional", "education", "online learning", "blended learning", "challenge", "obstacle", and "undergraduate". A Boolean approach was used to search for the relevant articles. The included papers were analysed using narrative approach. 


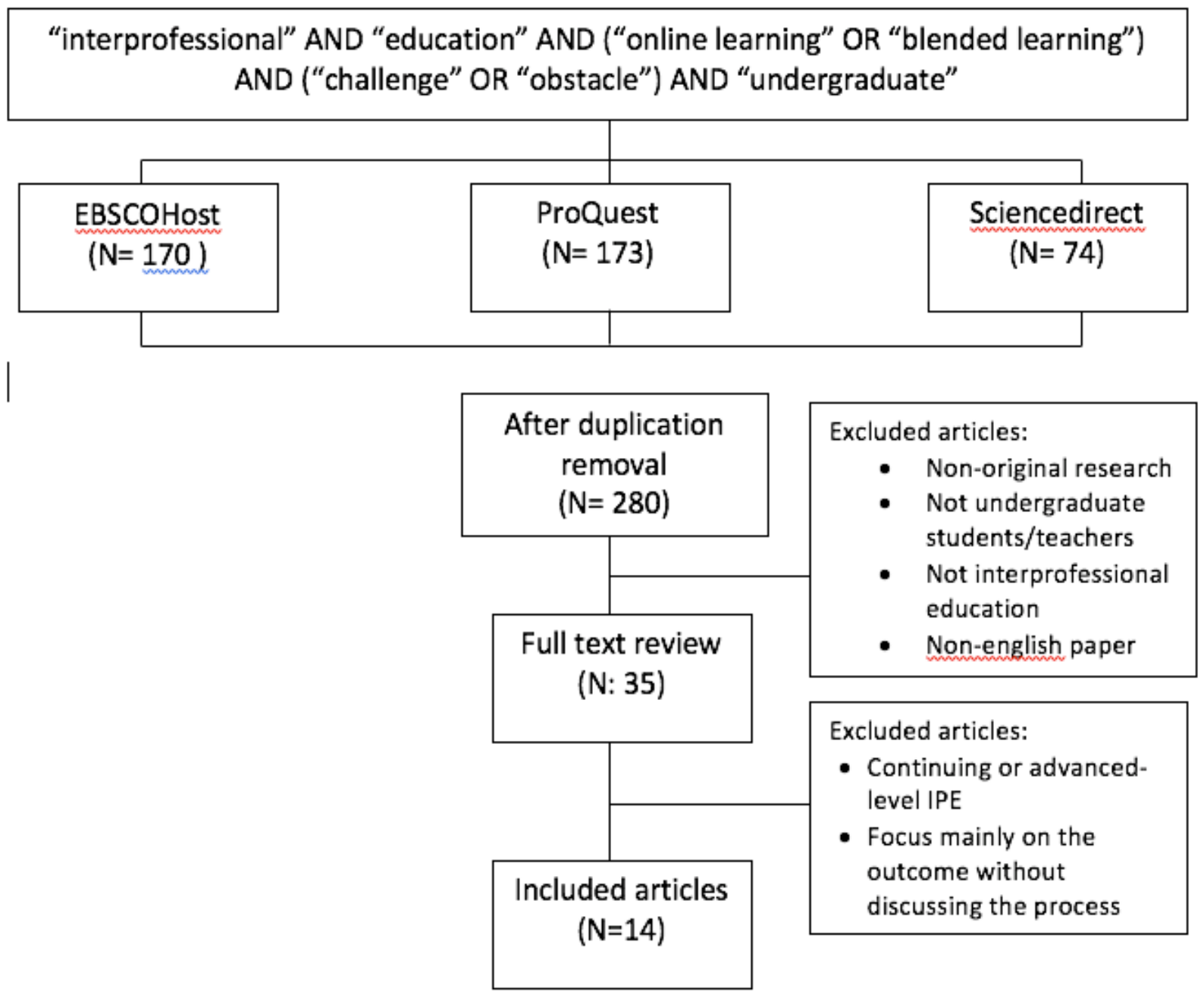

Figure 1. Article selection process

\section{RESULTS AND DISCUSSION}

There were fourteen articles included in the review. The papers addressed the key points and challenges upon implementing online IPE. Each article was scanned according to the research objective; identification of challenges, obstacles, as well as recommendation for future improvement. Relevant quotes from each articles were coded and interpreted. There were six themes generated through the interpretation process.

\section{Gaining support}

The foremost challenge to be considered is the institutional support and acceptance from the faculties. ${ }^{11}$ Commitment from the institution need to be secured prior to developing online learning for IPE. Interprofessional education, even in traditional face-to-face mode, requires huge effort and complex management. Embedding online environment to facilitate interprofessional learning is even more complex. Commitment from the institution and faculties to support online learning in IPE determine program success. Generous funding need to be made available $\mathrm{e}^{11-13}$ to develop the suitable learning resource i.e. online learning platform. Maintenance and daily monitoring should also be considered since the earlier budgeting stage. ${ }^{12}$ It is vital since common problems in using technology to facilitate learning occurs in technical basis. Apart from technical 
matter, institution is also responsible to facilitate faculty development program and provide reward to improve teachers quality and engagement. The teachers are responsible to operate the features and ensure the achievement of learning objective at the same time. Therefore, institution plays important role in ensuring faculty commitment and improving participation. Developing online learning for IPE program takes huge amount of funding and without commitment, the program could hardly be sustainable. $^{12}$

\section{Program design}

Incorporating online learning to teach students about interprofessional collaboration is highly challenging. Designing online learning for IPE needs interdisciplinary teamwork. ${ }^{14}$ It takes experts from health care professions education and technology. Functional teamwork and clear communication among blended expert team is critically important to make sure the online platform accommodate the curriculum well. Another challenge relies on developing the learning instruction. The teacher should consider how to ensure students self-directedness while collaborating with other professions. Self-directedness is the key to make online learning successful. However, the lacking of guideline ${ }^{11}$ in developing such program negatively influence the planning process. Not every teacher is ready to design online activities specifically to initiate collaborative competence. Accessibility of the learning platform along with network stability also play critically important factor in e-learning implementation. These should be taken into consideration when designing the curriculum and selecting the learning activities.

\section{Technical issues}

Proficiency in technology ${ }^{11,12,15-18}$ is the major technical issues for both the teachers as well as the students, be it during the synchronous or asynchronous sessions. The challenge during synchronous sessions for the teachers lies on their ability to provide appropriate feedback towards any non-verbal cues from each group member. This is important since

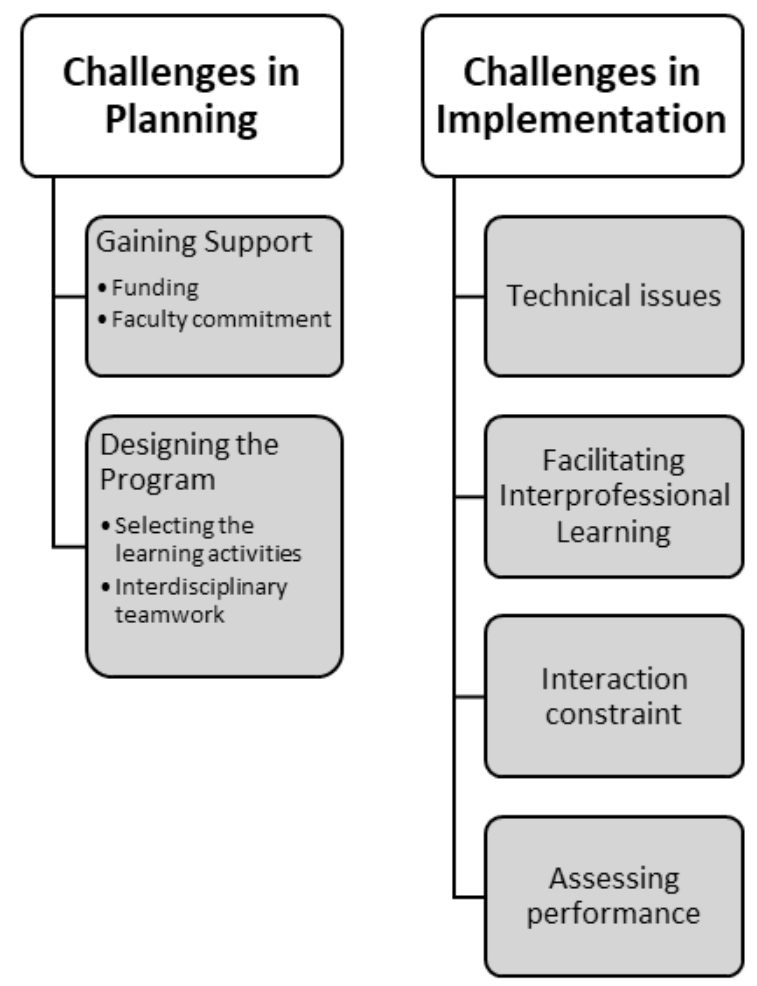

Figure 2. Common challenges in embedding online learning into IPE

the gist of IPE is teaching student to collaborate with other professions. Being unable to thoroughly see the students response as well as the actual team dynamic prevent the teachers to best facilitate the interprofessional team growth. In the asynchronous sessions, lacking of familiarity towards the platform creates trouble for both teachers and students, making the learning less effective. Navigating features in the e-learning platform requires skills and technical mastery which not all the teachers are well adapted. It negatively influence teachers confidence. Some teachers said that being slow in learning to operate the platform had made them feel inferior, thus affecting their perception in regard to the whole experience in facilitating IPE. Meanwhile, not every institution provide adequate support to assist teachers in navigating the platform. In such circumstances, more time and close progress monitoring needs to be allocated for preparations. Teachers should also be made aware of any potential errors as well as the troubleshooting procedures beforehand..$^{11,16,19-22}$ It is highly important for the institutions to provide a 
thorough technical instructions and manuals both for teachers and students. Apart from technology literacy, another problem arise is selecting the best features to support interprofessional teamwork..$^{11,23}$ The gist of IPE relies on the interaction among students from different professions. Therefore, a clear set of learning objectives for the IPE program should be discussed and agreed beforehand. In addition, adequate faculty development should be made priority in developing online learning for IPE, provided by experts in both technology and health professions education.

\section{Facilitating interprofessional learning}

As mentioned earlier, technical proficiency of the teachers hinders the learning facilitations. It influence the teachers in setting up the best learning experience to facilitate interprofessional learning for the students. ${ }^{17}$ Interprofessional learning itself is complex in nature. The students are expected to learn the the IPC competences by learning together. Scaffolding the IPC competences through online learning had become the major concern. ${ }^{16}$ The complexity of IPE along with the diversity of students professional background require greater effort for the teacher to provide the educational scaffolding. Although it is not impossible, scaffolding interprofessional learning in online environment should considers multiple factors, especially the learning support. The range of scaffolding activities includes tutorials, lectures, and modelling through video or game. Peer-assisted learning (PAL) is an alternative to help accommodating the scaffolding activity. It benefits the teachers by reducing the work load without compromising the program effectivity. Project exhibition followed by discussion and serial consultation could be facilitated by the senior students towards their juniors. A thorough planning for the PAL, of course, should be well discussed during the curriculum design. Peer-assisted learning argued to benefit the development of professional identity for the student tutors as well as the tutees. ${ }^{24}$ The well-acknowledged strength of PAL include sharing repertoire and mutual engagement, even if conducted online. ${ }^{25}$ Therefore, PAL could be used as a learning support to help students learn about role sharing to further develop their sense for interprofessional teamwork. Certain activities had been proven effective to improve online participation for collaborative learning. ${ }^{26}$ Group discussion and collaborative writing encourage multi-professional students to share of ideas. The role of facilitator at this point is providing triggers as well as gradual challenge for the students. By stimulating critical thinking through challenging questions, students are expected to step out of their professional boundaries and rebuild their orientation and understanding of the interprofessional teamwork. The use of attractive visuals could also improve participation rate. ${ }^{26}$ Teachers could also use the visual features provided in the platform, e.g. progress graphic for group performance based on the formative evaluation. By looking at the visuals, each group could monitor their own progress and reflect on any room for improvement. Again, the challenge here relies on the institutions support in providing and sustaining the faculty development program.

\section{Interaction constraint}

The challenge during the IPE process in online environment is the limitation in students interaction. 11,15,22,27 Interprofessional interaction among students is the heart of IPE. The quality of student interaction influence program effectiveness in promoting IPC competence. Activities such as group discussion and project-based collaborative activities facilitate collaborative learning and team building. Such activities previously relies on faceto-face interaction for a seamless teamwork and communication. Therefore, limited space for the students to interact with each other might interrupt the development of IPC competence. ${ }^{27}$

The main issue in regard to interaction constraint lies on the formation of interprofessional group. ${ }^{15}$ Performing collaborative work through technology in a distant space needs more time. It influences the group dynamic since students from each profession tend to stay in the comfort zone during the initial interaction. In a longitudinal IPE program, such condition would not cause a problem since the students would gradually adapt to the multiprofessional group and the interprofessional learning 
could progress. In a short IPE program, however, the condition would risk the program effectivity in improving IPC competence. Therefore, ensuring appropriate curriculum design in the micro level is important to overcome the negative influence of interaction constraint towards the achievement of the learning objectives ${ }^{22}$. Institutions also need to provide specific guidelines for the 'nettiquete' for both the teachers and students to facilitate professional behaviour development. ${ }^{15}$

\section{Assessing performance}

Due to limitation in students interaction, teachers found it was hard to evaluate the student performance. ${ }^{21}$ In face-to-face session, teachers could use cues based on students gesture to provide the most appropriate feedback. In online and distant environment, nonetheless, they found it hard to capture those cues. Teachers become unsure of how the students genuinely react towards the learning process. They would need a clear set of guide and rubric to perform student evaluation in online environment. The overarching goal of implementing IPE in undergraduate level is raising student awareness towards the importance of IPC. ${ }^{28}$ Improvement in perception and knowledge is the realistic indicators to evaluate the effectiveness of IPE in this level. Tangible changes in interprofessional collaborative performance could be evaluated in the long-term, if the competences were performed in the daily practice. Formative approach, nevertheless, is advisable to evaluate group performance. Technicalwise, the pitfall for using online system in assessing students is the possibility for any glitch or crash during or after the assessment. Certain precaution should be identified and developed prior to the implementation. Developing data management in detail during the logistic planning would be beneficial if any technical problem arise. Immediate data migration from the assessment platform could help avoiding the loss of data. ${ }^{29}$

\section{CONCLUSION}

Identifying challenges in developing online or blended learning for IPE program is important to ensure program effectiveness. Challenges and constraints in developing online learning for IPE range from planning through implementation. They might disrupt the interprofessional learning process and put the program mission into jeopardy. The main objective of IPE in undergraduate level is improving student perception about IPC. Inconvenient experiences in IPE program might result in negative reaction toward IPC. Therefore, a comprehensive preparation is critical to make the IPE program effective.

Defining the rationale of embedding online learning into IPE for undergraduate level is important to ensure the buy-ins from institution and faculties. Interdisciplinary teamwork should be well established in planning the program to make the program effective. Technical issues, including proficiency and accessibility, are the most common challenge in any online learning program. Faculty development and availability of manuals need to be prepared prior to program implementation to overcome any technical problems. Creativity in designing the micro curriculum and selecting the learning activity are necessary to engage students from multiple professions and thus improve the program effectiveness.

\section{RECOMMENDATION}

The study is limited in identifying challenges in developing online learning in IPE. Further study is needed to understand how the challenge or technical obstacle in online education influence the interprofessional learning. Through the review, a wide range of online activities in IPE were found. We need to scrutinize the appropriateness and feasibility of the learning activities in specific context. More studies are also encouraged to evaluate the learning outcomes or interprofessional competences that could be accomplished through online learning activities in IPE.

\section{COMPETING INTERESTS}

The authors declare that there are no competing interests related to this study. 


\section{LIST OF ABBREVIATIONS}

IPE: Interprofessional Education

IPC: Interprofessional Collaboration

LMS: Learning Management System

PAL: Peer-assisted Learning

\section{AUTHORS' CONTRIBUTION}

Rilani Riskiyana - developing review protocol, literature search, data analysis, and writing the publication manuscript.

\section{REFERENCES}

1. Reeves S, Fletcher S, McLoughlin C, Yim A, Patel $\mathrm{KD}$. Interprofessional online learning for primary healthcare: findings from a scoping review. BMJ open. 2017 Aug 1; 7(8): e016872. https:// bmjopen.bmj.com/content/bmjopen/7/8/ e016872.full.pdf

2. Evans SM, Ward C, Reeves S. Online interprofessional education facilitation: A scoping review. Medical teacher. 2019 Feb 1; 41(2): 21522. https://www.tandfonline.com/doi/full/10.1 080/0142159X.2018.1460656

3. Luk P, Tsang J, Tsoi HS, Chan K, Chen J. Collaborative Online Learning in Undergraduate Medical Education: A Scoping Review. https:// www.researchsquare.com/article/rs-28397/latest. pdf

4. Interprofessional Education Collaborative. Core competencies for interprofessional collaborative practice: 2016 update. Washington, DC: Interprofessional Education Collaborative; 2015.

5. McKenna L, Boyle M, Palermo C, Molloy E, Williams B, Brown T. Promoting interprofessional understandings through online learning: a qualitative examination. Nursing \& health sciences. 2014 Sep; 16(3): 321-6. https:// onlinelibrary.wiley.com/doi/pdf/10.1111/ nhs.12105

6. Solomon P, Baptiste S, Hall P, Luke R, Orchard C, Rukholm E, Carter L, King S, Damiani-Taraba G. Students' perceptions of interprofessional learning through facilitated online learning modules. Medical teacher. 2010 Sep 1; 32(9): e391-8. https://www.tandfonline.
com/doi/pdf/10.3109/0142159X.2010.495760

7. Blue AV, Charles L, Howell D, Koutalos Y, Mitcham M, Nappi J, Zoller J. Introducing students to patient safety through an online interprofessional course. Advances in medical education and practice. 2010; 1: 107. https://www. ncbi.nlm.nih.gov/pmc/articles/PMC3643135/

8. Schorn MN, Wu A, Davidson HA, Black E, Rockhold R. Interprofessional education (IPE): Synchronous, asynchronous, clinical practice, simulation across disciplines, across universities. Medical Science Educator. 2014 Dec 1; 24(1): 9-11. https://link.springer.com/article/10.1007/ s40670-014-0086-2

9. Riesen E, Morley M, Clendinneng D, Ogilvie S, Ann Murray M. Improving interprofessional competence in undergraduate students using a novel blended learning approach. Journal of interprofessional care. 2012 Jul 1; 26(4): 312-8. https://www.tandfonline.com/doi/abs/10.3109/ 13561820.2012 .660286

10. Myers CT, O'Brien SP. Teaching interprofessional collaboration: Using online education across institutions. Occupational therapy in health care. 2015 Apr 3; 29(2): 178-85. https://www. tandfonline.com/doi/pdf/10.3109/07380577.20 15.1017789

11. Cain J, Chretien K. Exploring social media's potential in interprofessional education. Journal of Research in Interprofessional Practice and Education. 2013 Aug 14; 3(2). https://jripe.org/ jripe/index.php/journal/article/viewFile/110/80

12. Fowler T, Phillips S, Patel S, Ruggiero K, Ragucci K, Kern D, Stuart G. Virtual interprofessional learning. Journal of Nursing Education. 2018 Nov 5; 57(11): 668-74. https://search.proquest.com/openview/ fc8b4c06631a71bbbc7ede5a4b324bbe/1.pdf

13. Djukic M, Adams J, Fulmer T, Szyld D, Lee S, Oh SY, Triola M. E-Learning with virtual teammates: A novel approach to interprofessional education. Journal of Interprofessional Care. 2015 Aug 28; 29(5): 476-82. http://www.nysimcenter. org/sites/default/files/nysimcenter/uploaded_ files/E-Learning-with-virtual-teammates-A-novelapproach.pdf 
14. Lowery B, Corbett RW, King CA, Brown ST, Faser Jr KE. Virtual clinic-opening the clinic door to interprofessional education and practice. The Journal for Nurse Practitioners. 2014 Nov 1; 10(10): e69-76. https://doi.org/10.1016/j. nurpra.2014.08.021

15. Hanna E, Soren B, Telner D, MacNeill H, Lowe M, Reeves S. Flying blind: The experience of online interprofessional facilitation. Journal of Interprofessional Care. 2013 Jul 1; 27(4): 298304. https://www.tandfonline.com/doi/abs/10. 3109/13561820.2012.723071

16. Pittenger AL, LimBybliw AL. Peer-led team learning in an online course on controversial medication issues and the US healthcare system. American journal of pharmaceutical education. 2013 Sep 12; 77(7). https://www.ajpe.org/ content/ajpe/77/7/150.full.pdf

17. Evans S, Knight T, Sønderlund A, Tooley G. Facilitators' experience of delivering asynchronous and synchronous online interprofessional education. Medical teacher. 2014 Dec 1; 36(12): 1051-6. http://www.academia.edu/ download/44975666/Facilitators_experience_ of_delivering_a20160421-26359-82lu88.pdf

18. Lotrecchiano GR, McDonald PL, Lyons L, Long T, Zajicek-Farber M. Blended learning: strengths, challenges, and lessons learned in an interprofessional training program. Maternal and child health journal. 2013 Nov 1; 17(9): 1725-34. https://link.springer.com/content/pdf/10.1007/ s10995-012-1175-8.pdf

19. Martini N, Caceres R. Triune case study: An exploration into inter-professional education (IPE) in an online environment supporting global health. International Journal of Innovation in Science and Mathematics Education (formerly CAL-laborate International). 2012 Oct 24; 20(3). https://openjournals.library.sydney.edu.au/ index.php/CAL/article/view/6445

20. Cannistraci P, Kehm B, Pieper BB, Speerschneider K, Farber SL, Storandt BC. Difficult to Doable: Interprofessional Collaborative Practice in Distance Education. Journal of Nursing
Education. 2018 Apr 4; 57(4): 225-8. https:// DOI.10.3928/01484834-20180322-06

21. Yeh VJ, Sherwood G, Durham CF, KardongEdgren S, Schwartz TA, Beeber LS. Designing and implementing asynchronous online deliberate practice to develop interprofessional communication competency. Nurse Education in Practice. 2019 Feb 1; 35: 21-6. https://doi. org/10.1016/j.nepr.2018.12.011

22. Turkelson C, Yorke AM, Keiser M, Smith L, Gilbert GE. Promoting Interprofessional Communication with Virtual Simulation and Deliberate Practice. Clinical Simulation in Nursing. 2020 Jul 25. https://doi.org/10.1016/j. ecns.2020.03.008

23. Sanborn H. Developing asynchronous online interprofessional education. Journal of interprofessional care. 2016 Sep 2; 30(5): 668-70. https://www.tandfonline.com/doi/abs/10.1080/ 13561820.2016.1182143

24. Burgess A, Nestel D. Facilitating the development of professional identity through peer assisted learning in medical education. Advances in medical education and practice. 2014; 5: 403. https://www.ncbi.nlm.nih.gov/pmc/articles/ PMC4217768

25. Watts $\mathrm{H}$, Malliris M, Billingham O. Online Peer Assisted Learning: Reporting on Practice. Journal of Peer learning. 2015; 8(8): 85-104. https://files. eric.ed.gov/fulltext/EJ1076440.pdf

26. Jin SH. Using visualization to motivate student participation in collaborative online learning environments. Journal of Educational Technology \& Society. 2017 Apr 1; 20(2): 51-62. https:// www.jstor.org/stable/10.2307/90002163

27. Poirier TI, Devraj R, Blankson F, Xin H. Interprofessional online global health course. American journal of pharmaceutical education. 2016 Nov 25; 80(9). https://www.ajpe.org/ content/ajpe/80/9/155.full.pdf

28. Thistlethwaite J. Interprofessional education: 50 years and counting. Medical education. 2016 Nov; 50(11): 1082-6. https://onlinelibrary.wiley.com/ doi/pdf/10.1111/medu.12959 
29. Ridgeway E. Collection Management, Assessment, and Development: Reviving Collections during LMS Implementation. The Serials Librarian.
2019 Jun 14; 76(1-4): 86-8. https://doi.org/10.1 080/0361526X.2019.1588613 